\title{
Psychometric properties of the Korean version of the medical outcomes study HIV health survey: results from a multicenter survey in Korea
}

Eun-Jung Shim ${ }^{1}$, Hyeju Ha ${ }^{1}$, Sun Hee Lee ${ }^{2}$, Nam Joong Kim³ ${ }^{3}$ Eu Suk Kim², Ji Hwan Bang ${ }^{5}$, Kyoung-Ho Song ${ }^{4}$, Bo Kyung Sohn ${ }^{6,7}$, Hye Youn Park ${ }^{8}$, Kyung-Lak Son ${ }^{9}$, Heesung Hwang ${ }^{10}$, Kwang-Min Lee ${ }^{11}$ and Bong-Jin Hahm ${ }^{9,10^{*}}$ (D)

\begin{abstract}
Background: Precise assessment of health-related quality of life (HRQOL) with a reliable and valid measure is a prerequisite to the enhancement of HRQOL. This study examined the psychometric properties of the Korean version of the Medical Outcomes Study HIV Health Survey (K-MOS-HIV).

Methods: The reliability and validity of the K-MOS-HIV were examined in a multicenter survey involving 201 outpatients with human immunodeficiency virus (HIV)/ acquired immunodeficiency syndrome (AIDS) from four teaching hospitals throughout Korea.

Results: Ceiling effects were observed in six subscales scores, particularly, for the role functioning (71.1\%), social functioning (63.2\%), and pain (48.8\%) scores. The Cronbach's a for the physical health summary and mental health summary were 0.90 and 0.94 , respectively, and it ranged from 0.78 to 0.95 for the subscales. The results of the exploratory structural equation modeling supported the two-factor structure of the K-MOS-HIV (physical health summary and mental health summary). An examination of the mean square statistics values from the Rasch analysis showed that the information-weighted fit and outlier-sensitive fit statistics were within the acceptable ranges of 0.6-1.4 except for two items in the mental health summary. The convergent validity of the K-MOS-HIV was supported by its significant positive correlations with the World Health Organization Quality of Life-HIV-BREF subscale scores. Its knowngroup validity was proven with its ability to detect significant differences in several K-MOS-HIV subscale scores among participants with different sociodemographic and clinical characteristics.
\end{abstract}

Conclusions: The K-MOS-HIV health survey appears to be a reliable and valid measure of HRQOL.

Keywords: Acquired immunodeficiency syndrome, Human immunodeficiency virus, Health-related quality of life, Item response theory, Medical outcomes study HIV health survey

\footnotetext{
*Correspondence: hahmbj@gmail.com; hahm@snu.ac.kr

${ }^{9}$ Department of Neuropsychiatry, Seoul National University Hospital, Seoul,

Republic of Korea

${ }^{10}$ Department of Psychiatry and Behavioral Sciences, Seoul National

University College of Medicine, Seoul, Republic of Korea

Full list of author information is available at the end of the article
}

(c) The Author(s). 2018 Open Access This article is distributed under the terms of the Creative Commons Attribution 4.0 International License (http://creativecommons.org/licenses/by/4.0/), which permits unrestricted use, distribution, and reproduction in any medium, provided you give appropriate credit to the original author(s) and the source, provide a link to the Creative Commons license, and indicate if changes were made. The Creative Commons Public Domain Dedication waiver (http://creativecommons.org/publicdomain/zero/1.0/) applies to the data made available in this article, unless otherwise stated. 


\section{Background}

As of 2015, 36.7 million persons are living with human immunodeficiency virus (HIV) worldwide [1]. With progress in treatment such as the introduction of highly active antiretroviral therapy (HAART), HIV has become a chronic illness with a significant decrease in HIV-related morbidity and mortality [2].

However, HIV/ acquired immunodeficiency syndrome (AIDS) still negatively affects the health-related quality of life (HRQOL) in people with HIV and AIDS (PLWHA) [3, 4]. HRQOL in PLWHA was significantly lower as compared to that of the general population [3] and those with other chronic diseases [5]. The stigma associated with HIV/AIDS is one worsening factor affecting HRQOL $[6,7]$. Moreover, according to a prospective cohort study, HRQOL, particularly physical QOL, was a prognostic factor of survival among persons with HIV [8]. As such, attention to HRQOL-related issues and clinical efforts to enhance HRQOL in PLWHA are warranted. The precise assessment of HRQOL with a reliable and valid measure is a prerequisite to improve HRQOL. The World Health Organization Quality of Life-HIV-BREF (WHOQOL-HIV BREF) [9], Functional Assessment of HIV infection quality of life instrument (FAHI) [10], and the Medical Outcomes Study HIV Health Survey (MOS-HIV) [11] are some of the HIV/ AIDS-specific tools that are used widely to assess the HRQOL of PLWHA. In particular, the FAHI and MOSHIV are considered two of the most appropriate HIVtargeted HRQOL measures [12].

Among them, the application of the MOS-HIV to assess HRQOL is useful in two ways. Firstly, it allows between-group comparisons (e.g., populations with other diseases and healthy populations) as the MOS-HIV was developed from generic MOS instruments. It also permits within-group and cross-cultural comparisons as it has been applied to PLWHA worldwide, enabling the use of a vast amount of accumulated data for such comparisons [13]. The feasibility of the use of the MOS-HIV has been proven $[14,15]$, and it has been validated in several languages such as Chinese [16, 17], French [18], German [18], Greek [19], Italian [20, 21], Spanish [14], Thai [22] and Luganda [23].

The number of PLWHA in South Korea is increasing consistently, with an average of 1000 new cases reported each year since 2011. As of 2016, the number of PLWHA was 11,439 [24]. However, research regarding HRQOL in Korean PLWHA is limited. The strong stigma associated with the disease is prominent in Korea, as is the lack of a standardized and valid HRQOL tool. These seem to be some of the reasons behind this paucity of HRQOL research on the Korean population. Until now, only the WHOQOL-HIV BREF [25] has been translated and validated in Korean, and there is no validated Korean version of the MOS-HIV health survey. Thus, the purpose of the present study was to examine the psychometric properties of the Korean version of the MOS-HIV health survey in a sample of PLWHA in Korea.

\section{Methods \\ Participants and procedures}

Participants consisted of 201 outpatients with HIV/AIDS recruited via consecutive sampling. This cross-sectional, multi-center survey implemented between December 2016 and June 2017 involved four university hospitals in South Korea (two located in Seoul, the capital city, and the other two in the cities of Seongnam and Busan). On the provision of informed consent, the participants were asked to complete the survey, and they could complete it either on site or take it home and return it by mail. A gift certificate (equivalent to \$9 U.S. dollars) was provided as a reward to all participants. This study was approved by the respective Institutional Review Boards of the participating institutions.

\section{Measures}

The MOS- HIV, developed by Albert Wu and colleagues, is a self-report measure to assess HRQOL for patients with HIV/AIDS [26]. It has 35 items evaluating the following 11 dimensions of HRQOL: general health perception; pain; physical functioning; role functioning; social functioning; energy/fatigue; mental health; health distress; cognitive functioning; quality of life; and health transition. It also provides two summary scores of physical health and mental health, calculated from the scores of 10 subscales, excluding the health transition subscale [27]. While the scores on the physical functioning, pain, and role functioning scores contribute more strongly to the physical health summary score, those on mental health, health distress, quality of life, and cognitive functioning contribute more strongly to the mental health summary score. Scores on general health perception, energy/fatigue, and social functioning contribute to both factors [27]. Respondents rate items on a three-, five- and six-point Likert scale, and on a dichotomous yes/no scale, with reference to the last 4 weeks. In accordance with the MOS-HIV scoring instructions [28], the 11 items are recoded, and subscale scores as well as the two summary scores are computed. The MOS-HIV scores range from 0 to 100 , with higher scores indicating better HRQOL.

The Korean version of the MOS-HIV (K-MOS-HIV) underwent a forward-backward translation procedure according to the European Organization for the Research and Treatment of Cancer translation guidelines [29]. Forward translation was performed by two independent clinicians, and the two versions of the Korean translation were integrated into a single version that underwent back-translation by an English speaker who 
has a good command of the Korean language and was blinded to the original version of the MOS-HIV. The developer of the MOS-HIV examined the back-translated version of the MOS-HIV and confirmed structural and semantic equivalence.

Moreover, the Korean version of the World Health Organization Quality of Life-HIV-BREF (K-WHOQOLHIV BREF) [9, 25] was used as a criterion measure to determine the convergent validity of the K-MOS-HIV. The WHOQOL-HIV BREF has 31 items with 29 items divided into six domains of HRQOL in PLWHA (i.e., physical QOL, psychological QOL, level of independence, social relationships, environment, and spiritual QOL) and two items assessing an individual's overall perception of QOL and health, respectively. Items are rated on a five-point Liker scale, and six domain scores are computed in accordance with the scoring guidelines [30]. Domain scores range from 4 to 20, with higher scores denoting higher QOL. The Cronbach's $\alpha$ of the KWHOQOL-HIV BREF is 0.94 [25].

Questions regarding sociodemographic data (i.e., age, sex, education, marital status, religion, employment, income, and insurance status) were included in a self-report survey. Clinical information (i.e., the Center for Disease Control and Prevention stage, years since diagnosis, CD4 cell counts, HIV RNA log, active antiretroviral therapy (ART) duration, psychological comorbidity, and medical comorbidity) were retrieved from medical records. A question regarding mode of transmission was also included in the survey, and participants were asked to choose among the options of sex with a person of the opposite sex, sex with a person of the same sex, and others.

\section{Statistical analyses}

To determine whether the scale had adequate range variability, the floor and ceiling effects of the K-MOSHIV were evaluated by examining percentages of scores at the extremes of the scaling range [19, 31].

The construct validity of the K-MOS-HIV was determined by examining its factorial and convergent validity. To determine its factorial validity, a confirmatory factor analysis (CFA) and exploratory structural equation modeling (ESEM) for a two-factor structure (physical health summary and mental health summary) were performed. In clinical research, many clinical symptoms or associated characteristics are likely to be associated with each other [32]. Therefore, the CFA, which requires the restriction of zero cross-loadings, might be restrictive, resulting in biased estimates [32, 33]. The ESEM, which is an integration of the best aspects of CFA, structural equation modeling, and exploratory factor analysis, does not require a strict restriction of zero cross-loading that causes over-estimated factor correlations and subsequent distorted structural relations [34]. Therefore, the modelfit of the CFA and ESEM for a two-factor structure was evaluated. The following criteria were applied to evaluate the goodness-of-fit indices of the factor models: standardized root mean square residual $(\mathrm{SRMR}) \leq .08$, comparative fit index $(\mathrm{CFI}) \geq .95$, Tucker-Lewis Index (TLI) $\geq .95$, root mean square error of approximation $(\mathrm{RMSEA}) \leq .08$, and $90 \%$ confidence interval $(\mathrm{CI})$ of RMSEA [35]. The factorial validity of the K-MOS-HIV was also examined by testing the partial credit model (PCM) in the polytomous model of a Rasch analysis [36]. The PCM is considered to be appropriate for analyzing responses in attitude or personality scales in which respondents rate their beliefs, or respond to statements on a multi-point scale [37]. The Rasch analysis provides two mean square (MNSQ) statistics, the outlier-sensitive fit statistic (outfit) and informationweighted fit statistic (infit) MNSQ. The outfit MNSQ is sensitive to outlier observations in the data, whereas the infit MNSQ is sensitive to unexpected inlying patterns among non-outlier observations. Therefore, the infit and outfit statistics were used to determine whether the item responses fit the expectations of the PCM. Both item MNSQ values of about 1.0 are considered ideal, and the values between 0.6 to 1.4 are deemed acceptable [38] Higher MNSQ values (e.g., > 1.4) indicate a lack of construct homogeneity with other items in a scale, while lower values (e.g., < 0.6) indicate potential redundancy of the item with the rest of the scale [38, 39].

The convergent validity of the K-MOS-HIV was examined by examining its correlations with the $\mathrm{K}$ WHOQOL-HIV BREF subscales scores. To examine known-group validity, $t$-tests or analyses of variance (ANOVA) were performed to examine whether the MOS-HIV scores differed among participants with varying sociodemographic and clinical characteristics that were known to be related to the HRQOL of PLWHA in a prior review [40]. Statistical analyses were performed using the IBM SPSS statistical package (version 23.0), Mplus software (version 7.4), and jMetrik (version 4.0.5).

\section{Results \\ Sociodemographic and clinical characteristics of participants}

The participants' characteristics in sociodemographic and clinical characteristics have been shown in Table 1. There were missing values (3 to 39 ) in all variables except age. The results of the Little's missing completely at random (MCAR) [41] test indicated that the missing values were MCAR, and thus they did not affect the analyses $\left(X^{2}{ }_{(785)}=50.42, p=1.00\right)$.

The mean age of participants was $48.49(S D=13.33)$ years. Majority of participants were male $(89.1 \%)$, not 
Table 1 Participant characteristics $(N=201)$

\begin{tabular}{|c|c|c|c|c|c|}
\hline & Total & Male $(n=179)$ & Female $(n=22)$ & & \\
\hline Variables & $N(\%)$ or $M(S D)$ & $N(\%)$ or $M(S D)$ & $N(\%)$ or $M(S D)$ & $x^{2} / t$ & $p$ \\
\hline \multicolumn{6}{|l|}{ Sociodemographic variables } \\
\hline Age $(n=201)$ & $48.49(13.33)$ & $47.35(13.13)$ & $57.73(11.41)$ & -3.54 & $<.001$ \\
\hline$\leq 40$ & $54(26.9)$ & $52(29.1)$ & $2(9.1)$ & 24.10 & $<.001$ \\
\hline $41-60$ & $107(53.2)$ & $100(55.9)$ & $7(31.8)$ & & \\
\hline$>60$ & $40(19.9)$ & $27(15.1)$ & $13(59.1)$ & & \\
\hline \multicolumn{6}{|l|}{ Education $(n=197)$} \\
\hline Less than high school & $45(22.8)$ & $30(17.1)$ & $15(68.2)$ & 30.09 & $<.001$ \\
\hline High school & $63(32.0)$ & $58(33.1)$ & $5(22.7)$ & & \\
\hline College or above & $89(45.2)$ & $87(49.7)$ & $2(9.1)$ & & \\
\hline \multicolumn{6}{|l|}{ Marital status $(n=191)$} \\
\hline Not married (single/divorced/widowed) & $142(74.3)$ & $127(75.1)$ & $15(68.2)$ & .50 & .48 \\
\hline Married & $49(25.7)$ & $42(24.9)$ & $7(31.8)$ & & \\
\hline \multicolumn{6}{|l|}{ Religion $(n=194)$} \\
\hline Yes & $106(54.6)$ & $91(52.9)$ & $15(68.2)$ & 1.84 & .18 \\
\hline No & $88(45.4)$ & $81(47.1)$ & $7(31.8)$ & & \\
\hline \multicolumn{6}{|l|}{ Employment $(n=190)$} \\
\hline Employed & $95(50.0)$ & $89(52.7)$ & $6(28.6)$ & 4.34 & $<.05$ \\
\hline Unemployed & $95(50.0)$ & $80(47.3)$ & $15(71.4)$ & & \\
\hline \multicolumn{6}{|l|}{ Income $(n=190)$} \\
\hline$\leq 1$ million Korean won (KRW) & $65(34.2)$ & $52(31.0)$ & $13(59.1)$ & 7.14 & $<.05$ \\
\hline 1-3 million KRW ${ }^{a}$ & $70(36.8)$ & $64(38.1)$ & $6(27.3)$ & & \\
\hline 3 million KRW & $55(28.9)$ & $52(31.0)$ & $3(13.6)$ & & \\
\hline \multicolumn{6}{|l|}{ Insurance $(n=176)$} \\
\hline National health insurance & $117(66.5)$ & $105(67.3)$ & $12(60.0)$ & .43 & .52 \\
\hline Medical aid & $59(33.5)$ & $51(32.7)$ & $8(40.0)$ & & \\
\hline \multicolumn{6}{|l|}{ Clinical variables } \\
\hline \multicolumn{6}{|l|}{ CDC Stage $(n=195)$} \\
\hline A (Asymptomatic) & $67(34.4)$ & $57(32.8)$ & $10(47.6)$ & 2.07 & .36 \\
\hline B (Symptomatic) & $68(34.9)$ & $63(36.2)$ & $5(23.8)$ & & \\
\hline C (AIDS) & $60(30.8)$ & $54(31.0)$ & $6(28.6)$ & & \\
\hline Years since diagnosis $(n=162)$ & $8.26(5.97)$ & $8.05(6.06)$ & $10.09(4.89)$ & -1.34 & .18 \\
\hline ART duration (year) $(n=187)$ & $7.09(5.37)$ & $6.89(5.54)$ & $8.91(3.10)$ & -2.44 & .02 \\
\hline CD4 cell counts $(n=198)$ & $649.09(306.96)$ & $642.24(314.01)$ & $703.91(242.24)$ & -.89 & .38 \\
\hline$<200$ cells $/ \mathrm{ml}$ & $9(4.5)$ & $9(5.1)$ & $0(.0)$ & 1.18 & .28 \\
\hline$\geq 200 \mathrm{cells} / \mathrm{ml}$ & $189(95.5)$ & $167(94.9)$ & $22(100.0)$ & & \\
\hline \multicolumn{6}{|l|}{ HIV RNA log $(n=198)$} \\
\hline Not detected & $139(70.2)$ & $123(69.9)$ & $16(72.7)$ & .24 & .97 \\
\hline$<40$ & $43(21.7)$ & $39(22.2)$ & $4(18.2)$ & & \\
\hline $40-2000$ & $9(4.5)$ & $8(4.5)$ & $1(4.5)$ & & \\
\hline$>2000$ & $7(3.5)$ & $6(3.4)$ & $1(4.5)$ & & \\
\hline \multicolumn{6}{|l|}{ Psychological comorbidity $(n=198)$} \\
\hline Yes & $30(15.2)$ & $25(14.2)$ & $5(22.7)$ & 1.11 & .29 \\
\hline No & $168(84.8)$ & $151(85.8)$ & $17(77.3)$ & & \\
\hline
\end{tabular}


Table 1 Participant characteristics ( $N=201)$ (Continued)

\begin{tabular}{|c|c|c|c|c|c|}
\hline & Total & Male $(n=179)$ & Female $(n=22)$ & & \\
\hline Variables & $N(\%)$ or $M(S D)$ & $N(\%)$ or $M(S D)$ & $N(\%)$ or $M(S D)$ & $x^{2} / t$ & $p$ \\
\hline \multicolumn{6}{|l|}{ Medical comorbidity $(n=198)$} \\
\hline Yes & $182(91.9)$ & $164(93.2)$ & $18(81.8)$ & 3.40 & .07 \\
\hline No & $16(8.1)$ & $12(6.8)$ & $4(18.2)$ & & \\
\hline \multicolumn{6}{|l|}{ Mode of transmission $(n=196)$} \\
\hline Sex with a person of the opposite sex & $60(30.6)$ & $44(25.3)$ & $16(72.7)$ & 23.77 & $<.001$ \\
\hline Sex with a person of the same sex & $106(54.1)$ & $104(59.8)$ & $2(9.1)$ & & \\
\hline Other & $30(15.3)$ & $26(14.9)$ & 4 (18.2) & & \\
\hline
\end{tabular}

${ }^{\mathrm{a}} 1-3$ million KRW $=$ equivalent to U.S. dollar \$872 - \$2616

married (74.3\%), educated up to college or higher (45. $2 \%$ ), professed a religion (54.6\%), and on the national health insurance plan (66.5\%). In terms of employment and income status, in general, participants were evenly distributed across categories.

As for clinical variables, approximately one-third of the participants were distributed at each of the following three stages of the Center for Disease Control and Prevention (CDC) classification system: A (asymptomatic), $\mathrm{B}$ (symptomatic), and C (AIDS). The mean for the number of years since diagnosis was $8.26(S D=5.97)$ years, and the mean duration of active antiretroviral treatment (ART) was $7.09(S D=5.37)$ years. The overall HIVrelated condition of the participants was good, with 95 . $5 \%$ having CD4 cell counts of $\geq 200$ cells $/ \mathrm{ml}$, and $70.2 \%$ having HIV RNA log (viral load) not detected. However, the rate of medical comorbidity was high (91.9\%), while that of psychological comorbidity was $15.2 \%$. Among the 30 participants who had psychological comorbidity, 24 had major depressive disorder, 1 had bipolar I disorder, 3 had insomnia, 1 had snoring/sleep apnea, and 1 had cognitive dysfunction problems. Additionally, majority of the participants were infected via sexual transmission, with $30.6 \%$ by heterosexual transmission and $54.1 \%$ by same sex transmission.

The examination of the sociodemographic and clinical characteristics by sex indicated significant differences between male and female participants in terms of age, education, employment, income, ART duration, and mode of transmission. Specifically, male participants were younger, had a higher percentage of college or above education, and were employed. With reference to income, the overall percentage of an income less than 1 million Korean Won (equivalent to U.S. dollar \$872) was higher among female participants. The mean for the number of years of ART duration was shorter in male participants. For mode of transmission, the percentage of heterosexual transmission was higher among female, and that of the same sex transmission was higher among male participants.

\section{Scale properties and internal consistency of the K-MOS-HIV}

The descriptive statistics for the subscale scores and the data on information for floor and ceiling effects have been presented in Table 2. The mean scores of the KMOS-HIV subscale scores ranged from 53.42 (general health perception) to 85.87 (social functioning). Further, while a moderate flooring effect $(>15 \%)$ was observed for the role functioning scores (20.9\%), substantial ceiling effects were observed in six subscales scores, especially for the role functioning (71.1\%), social functioning (63.2\%), and pain $(48.8 \%)$ scores.

The Cronbach's $\alpha$ of the K-MOS-HIV scales as a measure of internal consistency, was satisfactory overall, with values ranging from 0.78 to 0.95 across subscales. Further, those for the physical health summary and the mental health summary were 0.90 and 0.94 , respectively.

\section{Construct validity of the K-MOS-HIV: Factorial and convergent validity}

The results of the CFA examining the factorial validity of the K-MOS-HIV indicated that the proposed two-factor structures (physical health summary and the mental health summary) represented by the subscales of the MOS-HIV showed unsatisfactory goodness of fit indices $\left(X^{2}{ }_{(32)}=501.9, p<.001, \mathrm{RMSEA}=.270[.250-.291], \mathrm{CFI}\right.$ $=.608, \mathrm{TLI}=.449$, and SRMR $=1.367)$. On the other hand, the results of the ESEM (Fig. 1), which specified a residual correlation between general health perception and social functioning (modification index $=13.65$, standardized expected parameter change $=-.34)$, demonstrated an adequate fit to the data $\left(X^{2}{ }_{(25)}=56.2, p<.001\right.$, RMSEA $=.079[.051-.106], \mathrm{CFI}=.974, \mathrm{TLI}=.953$, and SRMR $=.027$ ). While social functioning, role functioning, and physical functioning loaded on the physical health summary, mental health, quality of life, energy/fatigue, health distress, and cognitive functioning loaded on the mental health summary (Table 3). General health perception and pain loaded more on the physical health 
Table 2 Scale properties and internal consistency of the K-MOS-HIV and correlations between K-MOS-HIV and K-WHOQOL-HIV BREF

\begin{tabular}{|c|c|c|c|c|c|c|c|c|c|c|c|c|c|}
\hline \multirow[b]{2}{*}{ K-WHOQOL-HIV BREF } & \multicolumn{13}{|c|}{ K-MOS-HIV } \\
\hline & $\mathrm{GHP}$ & $P$ & PF & RF & SF & $\mathrm{EF}$ & $\mathrm{MH}$ & $\mathrm{HD}$ & $\mathrm{CF}$ & $\mathrm{QL}$ & HT & $\mathrm{PHS}$ & MHS \\
\hline Overall QOL & $.63^{* *}$ & $.34^{* *}$ & $.32^{* *}$ & $.46^{* *}$ & $.36^{* *}$ & $.62^{* *}$ & $.65^{* *}$ & $.58^{* *}$ & $.41^{* *}$ & $.73^{* *}$ & $.38^{* *}$ & $.48^{* *}$ & $.72^{* *}$ \\
\hline General health & $.75^{* *}$ & $.46^{* *}$ & $.37^{* *}$ & $.53^{* *}$ & $.44^{* *}$ & $.65^{* *}$ & $.61^{* *}$ & $.68^{* *}$ & $.45^{* *}$ & $.62^{* *}$ & $.32^{* *}$ & $.59^{* *}$ & $.73^{* *}$ \\
\hline Physical QOL & $.73^{* *}$ & $.58^{* *}$ & $.49^{* *}$ & $.54^{* *}$ & $.51^{* *}$ & $.74^{* *}$ & $.72^{* *}$ & $.75^{* *}$ & $.54^{* *}$ & $.65^{* *}$ & $.31^{* *}$ & $.67^{* *}$ & $.81^{* *}$ \\
\hline Psychological QOL & $.66^{* *}$ & $.44^{* *}$ & $.35^{* *}$ & $.47^{* *}$ & $.39^{* *}$ & $.72^{* *}$ & $.71^{* *}$ & $.59^{* *}$ & $.51^{* *}$ & $.69^{* *}$ & $.35^{* *}$ & $.53^{* *}$ & $.76^{* *}$ \\
\hline Level of independence & $.68^{* *}$ & $.46^{* *}$ & $.57^{* *}$ & $.65^{* *}$ & $.47^{* *}$ & $.68^{* *}$ & $.62^{* *}$ & $.58^{* *}$ & $.48^{* *}$ & $.55^{* *}$ & $.41^{* *}$ & $.71^{* *}$ & $.68^{* *}$ \\
\hline Social relationships & $.53^{* *}$ & $.41^{* *}$ & $.40^{* *}$ & $.44^{* *}$ & $.44^{* *}$ & $.59^{* *}$ & $.59^{* *}$ & $.50^{* *}$ & $.41^{* *}$ & $.55^{* *}$ & $.24^{* *}$ & $.53^{* *}$ & $.63^{* *}$ \\
\hline Environment & $.50^{* *}$ & $.44^{* *}$ & $.40^{* *}$ & $.41^{* *}$ & $.36^{* *}$ & $.59^{* *}$ & $.55^{* *}$ & $.48^{* *}$ & $.36^{* *}$ & $.55^{* *}$ & $.23^{* *}$ & $.51^{* *}$ & $.59^{* *}$ \\
\hline \multirow[t]{2}{*}{ Spirituality } & $.53^{* *}$ & $.32^{* *}$ & $.22^{* *}$ & $.37^{* *}$ & $.36^{* *}$ & $.63^{* *}$ & $.63^{* *}$ & $.64^{* *}$ & $.52^{* *}$ & $.57^{* *}$ & $.27^{* *}$ & $.39^{* *}$ & $.71^{* *}$ \\
\hline & & & & & & & & & & & & \multicolumn{2}{|l|}{ Range } \\
\hline M & 53.42 & 83.80 & 76.75 & 75.63 & 85.87 & 60.39 & 65.16 & 70.75 & 79.40 & 56.72 & 55.10 & \multirow{2}{*}{$\begin{array}{l}24.08 \\
-64.77\end{array}$} & \multirow{2}{*}{$\begin{array}{l}14.13 \\
-65.88\end{array}$} \\
\hline$S D$ & 24.11 & 20.79 & 25.11 & 40.87 & 22.44 & 20.50 & 21.19 & 27.79 & 20.67 & 22.04 & 19.74 & & \\
\hline Cronbach's a & 0.88 & 0.82 & 0.86 & 0.90 & - & 0.78 & 0.78 & 0.95 & 0.89 & - & - & 0.90 & 0.94 \\
\hline No. of Items & 5 & 2 & 6 & 2 & 1 & 4 & 5 & 4 & 4 & 1 & 1 & & \\
\hline$\%$ Floor & 3.0 & 2.5 & 0.5 & 20.9 & 1.5 & 1.0 & 0.5 & 1.5 & 0.5 & 5.0 & 3.0 & & \\
\hline \% Ceiling & 2.5 & 48.8 & 33.8 & 71.1 & 63.2 & 3.0 & 3.5 & 24.4 & 25.4 & 5.5 & 8.5 & & \\
\hline
\end{tabular}

GHP General Health Perception, $P$ Pain, PF Physical Functioning, RF Role Functioning, SF Social Functioning, MH Mental Health, EF Energy/Fatigue, HD Health Distress, CF Cognitive Functioning, QL Quality of Life, HT Health Transition, PHS Physical Health Summary Score, MHS Mental Health Summary Score; ${ }^{* *} p<.01$ † Sample size varies from 193 to 201 due to missing data

summary, but it also loaded to a lesser degree on the mental health summary.

The convergent validity of the K-MOS-HIV was demonstrated by its significant positive correlations with the K-WHOQOL-HIV BREF subscale scores. All correlations were significant (Table 2) and the correlation coefficients ranged from .22 to .81 . Both the physical and psychological domain scores of the K-WHOQOLHIV BREF were significantly correlated with the respective physical health summary $(r=.67, p<.01)$ and mental

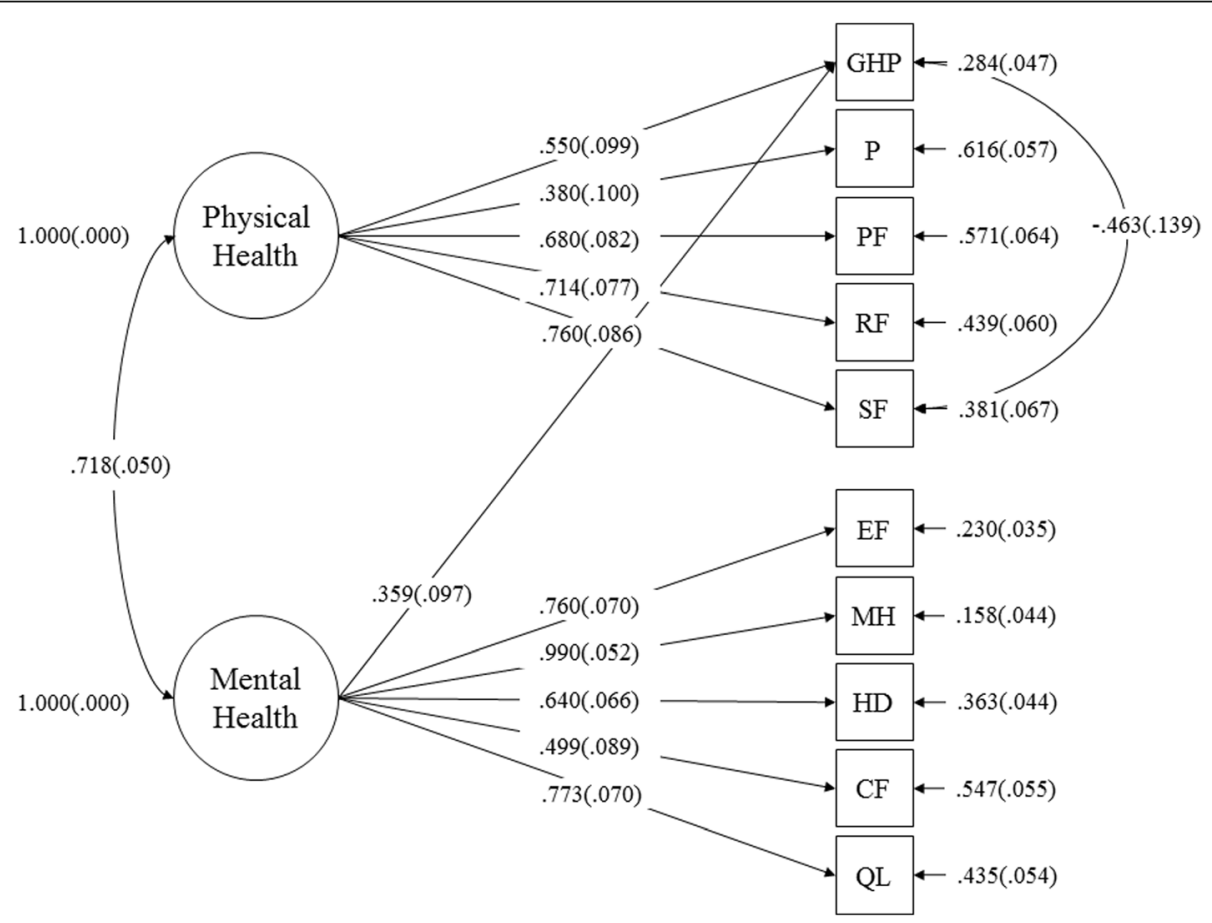

Fig. 1 Standardized estimates in the exploratory structural equation modeling of the K-MOS-HIV $(N=201)$ 
Table 3 Factor loading matrix of the ESEM model $(N=201)$

\begin{tabular}{|c|c|c|}
\hline Scales & PHS & MHS \\
\hline General health perception & $.55^{* * *}$ & $.36 * *$ \\
\hline Pain & $.38^{* * *}$ & $.29^{* *}$ \\
\hline Physical functioning & $.68^{* * *}$ & -.04 \\
\hline Role functioning & $.71^{* * * *}$ & -.05 \\
\hline Social functioning & $.76^{* * *}$ & -.04 \\
\hline Energy/Fatigue & $.15^{*}$ & $.76^{* * *}$ \\
\hline Mental health & -.10 & $.99^{* * *}$ \\
\hline Health distress & $.20^{* *}$ & $.64^{* * *}$ \\
\hline Cognitive functioning & $.22^{*}$ & $.50^{* * *}$ \\
\hline Quality of life & .03 & $.77^{* * *}$ \\
\hline
\end{tabular}

Factor loading with magnitudes $>.35$ have been shown in bold; ${ }^{*} p<.05$, ${ }^{* *} p<.01,{ }^{* * *} p<.001$

health summary scores $(r=.76, p<.01)$. However, the correlation of the K-WHOQOL-HIV BREF physical domain score with the mental health summary of the KMOS-HIV $(r=.81, p<.01)$ was slightly stronger as compared to the physical health summary of the K-MOS-HIV.

\section{Results of Rasch analysis}

The results of the Rasch analysis have been shown in Table 4. The data from participants with missing responses on one or more items were excluded from the Rasch analysis $(n=16)$. To evaluate the content homogeneity or unidimensionality of the items within each identified factor, the Rasch measurement model was used. Following the results of the ESEM supported the two-factor structure of the K-MOS-HIV, the Rasch analysis was performed for these two factors.

On the physical health summary, all the items had a good fit, with the infit MNSQ ranging from 0.69 to 1.37 and outfit MNSQ ranging from 0.50 to 1.37 . On the mental health summary, two items had both infit and outfit statistics greater than 1.4: the mental health $8 \mathrm{~b}$ had an infit of 1.80 and outfit of 2.27; the mental health $8 \mathrm{~d}$ had an infit of 1.47 and outfit of 1.54 . All other items on the mental health summary demonstrated good fit, with the infit MNSQ ranging from 0.65 to 1.30 and outfit MNSQ ranging from 0.61 to 1.33 .

The results regarding item difficulties and the step parameters for the 34 items indicated that not all items in all the scales maintain the given step orders. In majority of the items, only two-step values were not ordered. For instance, the four step parameters of the item Pain 3 were $-1.44,-0.68,1.14$, and 0.98 , showing that only the third (1.14) and fourth (0.98) steps were dislocated. However, six items showed that at least three step estimates were disordered (e.g., $-0.36,-0.72,-0.81,0.87$, and 1.02 for the item Health Distress 9e).

\section{Known-group validity}

The results of the $t$-tests or ANOVAs conducted to examine the ability of the K-MOS-HIV to detect potential differences in various dimensions of HRQOL among participants with different sociodemographic and clinical characteristics have been summarized in Table 5. In terms of sociodemographic variables, a number of subscale scores showed significant differences among groups formed by age, marital status, employment, monthly income and insurance status.

Age was associated with the physical functioning and social functioning subscales, $F_{(2,198)}=9.67$ and 3.74 , and the physical health summary, $F_{(2,198)}=5.01$. However, for the social functioning subscale, the post-hoc analysis revealed that the between-group difference was not significant. For marital status, the subscale scores on social functioning, energy/fatigue, and Mental Health as well as the mental health summary were higher among married participants than non-married counterparts, $t$ $(189)=2.24,2.60,2.26$, and 2.00, respectively. Employed participants showed higher scores, as compared to their unemployed counterparts, on eight dimensions of the KMOS-HIV (general health perception, physical functioning, role functioning, social functioning, energy/fatigue, mental health, health distress, and cognitive functioning) as well as on the two summary scores of physical health and mental health, $t_{(188)}=2.92,5.30,4.11,2.65,2.80$, $2.40,2.91,3.33,4.29$, and 3.09, respectively. Participants with higher income showed higher scores than did those with lower income on all 10 MOS-HIV subscales and on the physical health summary and mental health summary, $F_{(2,187)}=10.00,5.60,23.80$, $13.17,4.50,7.31,4.78,5.60,5.27,3.24,19.68$, and 6 . 63, respectively. Furthermore, the participants on the national health insurance plan showed a better QOL than those with medical aid, showing similar patterns as those observed in employment, $t_{(174)}=3.75,5.06$, $3.50,3.13,2.31,2.17,2.36,2.18,4.87$; and 2.50, respectively.

With reference to the clinical variables, participants with a CD4 cell count of above 200 cells $/ \mathrm{ml}$ showed higher scores on five subscales (general health perception, physical functioning, role functioning, social functioning, and energy/fatigue) and on the physical health summary, $t_{(196)}=2.76,2.30,2.27,2.30,1.99$, and 2.91, respectively. The social functioning scores differed according to viral load status $\left(F_{(3,194)}=3.07\right)$ and ART duration, $t_{(185)}=-2.52$. Additionally, participants with a shorter ART duration and years since diagnosis showed higher health transition scores, $t_{(185)}=3.02$ and $t_{(160)}=$ 2.85 , respectively. Participants with a comorbid psychiatric disorder showed lower scores on five subscales (energy/fatigue, mental health, health distress, cognitive functioning, and quality of life) and on the mental health 
Table 4 Infit and outfit MNSQ statistics, item difficulties, and step parameters for each item $(N=185)$

\begin{tabular}{|c|c|c|c|c|c|c|c|c|}
\hline Item & Infit & Outfit & Diff. & Step 1 & Step 2 & Step 3 & Step 4 & Step 5 \\
\hline \multicolumn{9}{|l|}{ PHS } \\
\hline GHP 1 & 1.07 & 1.09 & 1.68 & -3.41 & -1.60 & 1.40 & 3.61 & - \\
\hline P2 & 1.37 & 1.37 & -0.87 & -1.48 & -1.15 & 0.37 & 0.63 & 1.63 \\
\hline P3 & 0.97 & 1.04 & -1.19 & -1.44 & -0.68 & 1.14 & 0.98 & - \\
\hline PF 4a & 1.01 & 1.04 & 0.54 & -1.12 & 1.12 & - & - & - \\
\hline PF 4b & 0.84 & 0.76 & -0.24 & -0.74 & 0.74 & - & - & - \\
\hline PF 4c & 0.96 & 1.18 & -0.09 & -0.96 & 0.96 & - & - & - \\
\hline PF 4d & 0.91 & 0.70 & -0.47 & -0.79 & 0.79 & - & - & - \\
\hline PF 4e & 1.12 & 0.80 & -0.93 & 0.20 & -0.20 & - & - & - \\
\hline PF $4 f$ & 1.30 & 0.83 & -1.02 & 1.45 & -1.45 & - & - & - \\
\hline RF 5 & 0.69 & 0.50 & -0.41 & - & - & - & - & - \\
\hline RF 6 & 0.73 & 0.54 & -0.23 & - & - & - & - & - \\
\hline SF 7 & 0.95 & 0.99 & -0.81 & 0.25 & -1.32 & -0.51 & 0.93 & 0.65 \\
\hline GHP 11a & 0.96 & 0.93 & 1.06 & -2.21 & -0.17 & -0.23 & 2.61 & \\
\hline GHP 11b & 1.19 & 1.20 & 1.01 & -2.22 & -0.43 & -0.66 & 3.31 & \\
\hline GHP 11c & 1.05 & 1.00 & 1.36 & -2.35 & -0.40 & -0.59 & 3.34 & \\
\hline GHP 11d & 1.16 & 1.27 & 0.61 & -1.82 & -0.06 & -0.37 & 2.25 & \\
\hline \multicolumn{9}{|l|}{ MHS } \\
\hline MH 8a & 0.75 & 0.66 & -0.45 & -1.15 & -0.24 & -0.34 & 0.61 & 1.12 \\
\hline $\mathrm{MH} 8 \mathrm{~b}$ & 1.80 & 2.27 & 0.74 & -1.26 & -0.79 & 0.48 & -0.14 & 1.71 \\
\hline $\mathrm{MH} 8 \mathrm{c}$ & 0.74 & 0.75 & -0.16 & -0.96 & -0.78 & -0.57 & 1.07 & 1.25 \\
\hline MH 8d & 1.47 & 1.54 & 0.82 & -1.14 & -0.81 & 0.15 & 0.62 & 1.18 \\
\hline MH 8e & 1.25 & 1.07 & -0.36 & -0.98 & -0.59 & -0.05 & 0.60 & 1.02 \\
\hline EF 9a & 1.13 & 1.13 & 0.76 & -2.16 & -1.16 & 0.45 & 1.17 & 1.69 \\
\hline $\mathrm{EF} 9 \mathrm{~b}$ & 0.82 & 0.84 & -0.25 & -0.77 & -0.96 & -0.64 & 0.72 & 1.65 \\
\hline EF $9 c$ & 0.90 & 0.92 & 0.16 & -1.60 & -1.45 & -0.18 & 1.02 & 2.21 \\
\hline EF 9d & 1.30 & 1.28 & 0.59 & -1.38 & -1.14 & 0.17 & 0.94 & 1.41 \\
\hline HD 9e & 0.73 & 0.73 & 0.01 & -0.36 & -0.72 & -0.81 & 0.87 & 1.02 \\
\hline HD gf & 0.70 & 0.63 & -0.02 & -0.41 & -0.70 & -0.48 & 0.72 & 0.88 \\
\hline $\mathrm{HD} 9 \mathrm{~g}$ & 0.65 & 0.61 & -0.08 & -0.44 & -0.33 & -0.69 & 0.93 & 0.53 \\
\hline $\mathrm{HD} 9 \mathrm{~h}$ & 0.91 & 0.88 & 0.01 & -0.76 & -0.57 & -0.31 & 0.52 & 1.12 \\
\hline CF 10a & 0.79 & 1.33 & -0.28 & -0.10 & -0.73 & -0.49 & 0.55 & 0.77 \\
\hline CF 10b & 1.22 & 1.24 & -0.55 & -0.52 & -1.00 & -0.76 & 0.91 & 1.37 \\
\hline CF $10 \mathrm{c}$ & 0.86 & 0.78 & -0.69 & -1.20 & -0.19 & -0.79 & 0.85 & 1.34 \\
\hline CF 10d & 0.93 & 0.84 & -0.93 & -0.62 & -1.41 & -0.25 & 1.11 & 1.17 \\
\hline QL 12 & 0.82 & 0.82 & 0.67 & -1.50 & -2.17 & 0.68 & 3.00 & - \\
\hline
\end{tabular}

GHP General Health Perception, P Pain, PF Physical Functioning, RF Role Functioning, SF Social Functioning, MH Mental Health, EF Energy/Fatigue, HD Health Distress, CF Cognitive Functioning, QL Quality of Life, PHS Physical Health Summary Score, MHS Mental Health Summary Score Infit and outfit MNSQ statistics higher than 1.4 or lower than 0.6 as well as disordered step parameters are shown in bold

summary, $t_{(196)}=-2.79,-2.85,-2.44,-3.10,-2.08$, and -3.12 , respectively. Moreover, participants with a medical comorbidity showed lower scores on three subscales (physical functioning, role functioning, and social functioning), and on the physical health summary, $t_{(196)}$ $=-2.04,-4.63,-2.19$, and -4.07 , respectively.
Discussion

This study examined the reliability and validity of the KMOS-HIV in a multicenter study involving 201 outpatients with HIV/AIDS in Korea.

Firstly, ceiling effects were observed in six subscales, particularly in role functioning $(71.1 \%)$, social functioning 
Table 5 Known-group validity of the K-MOS-HIV

\begin{tabular}{|c|c|c|c|c|c|c|c|c|c|c|c|c|c|}
\hline & \multicolumn{11}{|c|}{ Scale ${ }^{a, b}$} & \multirow[t]{2}{*}{$\mathrm{PHS}^{\mathrm{a}, \mathrm{b}}$} & \multirow[t]{2}{*}{$M \mathrm{MS}^{\mathrm{a}, \mathrm{b}}$} \\
\hline & $\overline{G H P}$ & $P$ & $\mathrm{PF}$ & $\mathrm{RF}$ & SF & $\mathrm{EF}$ & $\mathrm{MH}$ & $\mathrm{HD}$ & CF & QL & $\overline{\mathrm{HT}}$ & & \\
\hline \multicolumn{14}{|l|}{ Sociodemographic variables } \\
\hline $\mathrm{Age}^{\mathrm{a}}$ & & & $* * *$ & & * & & & & & & & $* *$ & \\
\hline \multicolumn{14}{|l|}{ Sex } \\
\hline \multicolumn{14}{|l|}{ Education } \\
\hline Marital status ${ }^{b}$ & & & & & $* *$ & * & * & & & & & & $*$ \\
\hline \multicolumn{14}{|l|}{ Religion } \\
\hline Employment $^{\mathrm{b}}$ & $* *$ & & $* * *$ & $* * *$ & $* *$ & $* *$ & * & $* *$ & $* * *$ & & & $* * *$ & $* *$ \\
\hline Income $e^{c}$ & $* * *$ & $* *$ & $* * *$ & $* * *$ & $*$ & $* * *$ & $* *$ & $* *$ & $* *$ & $*$ & & $* * *$ & $* *$ \\
\hline Insurance ${ }^{b}$ & $* * *$ & & $* * *$ & $* *$ & $* *$ & * & * & * & * & & & $* * *$ & * \\
\hline \multicolumn{14}{|l|}{ Clinical variables } \\
\hline \multicolumn{14}{|l|}{ CDC stage } \\
\hline Years since diagnosis ${ }^{\mathrm{b}}$ & & & & & & & & & & & $* *$ & & \\
\hline ART duration ${ }^{d}$ & & & & & * & & & & & & $* *$ & & \\
\hline CD4 cell counts ${ }^{b}$ & $* *$ & & * & * & * & * & & & & & & $* *$ & \\
\hline HIV RNA $\log ^{e}$ & & & & & * & & & & & & & & \\
\hline Psychological Comorbidity ${ }^{b}$ & & & & & & $* *$ & $* *$ & * & $* *$ & * & & & $* *$ \\
\hline Medical Comorbidity ${ }^{\mathrm{b}}$ & & & $* *$ & $* * *$ & $*$ & & & & & & & $* * *$ & \\
\hline Mode of transmission & & & & & & & & & & & & & \\
\hline
\end{tabular}

GHP General Health Perception, P Pain, PF Physical Functioning, RF Role Functioning, SF Social Functioning, MH Mental Health, EF Energy/Fatigue, HD Health Distress, CF Cognitive Functioning, QL Quality of Life, HT Health Transition; ${ }^{*} p<.05,{ }^{* *} p<.01,{ }^{* * *} p<.001$

†Sample size varies from 162 to 201 due to missing data;

${ }^{a}$ The post hoc (Bonferroni) tests indicated that PF $(1>2=3)$ and PHS $(1>2) .1=(\leq 40), 2=(41-60), 3=(>60)$

${ }^{\mathrm{b}}$ All results indicate that $1>2 ; 1=$ married, $2=$ not married; $1=$ employed, $2=$ unemployed; $1=$ National health insurance, $2=$ medical aid; $1=(Y e a r s$ since diagnosis $\leq$ mean), $2=$ (Years since diagnosis $>$ mean $) ; 1=\left(C D 4 \geq 200 / \mathrm{mm}^{3}\right), 2=\left(C D 4<200 / \mathrm{mm}^{3}\right) ; 1=$ Comorbidity no, $2=$ Comorbidity yes

${ }^{c}$ All post hoc Bonferroni tests indicated that $1<2=3$, with the exceptions of $\mathrm{P}(1<3)$ and SF $(1<2) .1=(\leq 1$ million KRW $), 2=(1-3$ million KRW $), 3=(>3$ million KRW $)$

${ }^{\mathrm{d}} \mathrm{SF}(1<2)$ and HT $(1>2) .1=$ (ART duration $\leq$ mean), $2=$ (ART duration $>$ mean)

'The post hoc (Bonferroni) tests indicated that $1>2=3=4 ; 1=($ Not detected), $2=(<40), 3=(40-2000), 4=(>2000)$

(63.2\%), and pain (48.8\%), while a floor effect was observed in role functioning $(20.9 \%)$. The observed pattern of these effects (e.g., ceiling effects for role functioning, social functioning, and pain) is line with the results obtained from validation studies of the MOS-HIV in several languages $[16,19,42]$. For example, ceiling effects in role functioning (79\%), social functioning (76\%) and floor effect in role functioning (14.5\%) were reported in the Thai version of the MOS-HIV [22]. The ceiling effects observed in the present study might be related to the relatively good level of HIV-related condition of the participants, as evidenced by clinical characteristics such as $95.5 \%$ of the participants having CD4 cell counts of $\geq 200$ cells/ml and $92 \%$ having an HIV RNA log value less than 40. In fact, majority of the participants in previous studies that reported similar patterns of ceiling or floor effects had CD4 cell counts of $>200$ cells/ml $[19,42]$. On the other hand, floor effects in social functioning (21.2\%) and role functioning (72.6\%) were observed in the Italian version of the MOSHIV [20], with only $7.6 \%$ of participants having CD4 cell counts of $>200$ cells $/ \mathrm{ml}$ [20].
Regarding the factorial validity of the K-MOS-HIV, the results of the ESEM supported its previously proposed two-factor structure (physical health summary and mental health summary) [27]. However, the loading patterns of subscales of the physical health summary and mental health summary were somewhat different. For instance, in Revicki et al.'s study [27], pain, role functioning, and physical functioning loaded on the physical health summary, while mental health, health distress, quality of life and cognitive functioning loaded on the mental health summary, and general health perception, social functioning and energy/fatigue loaded on both factors. However, in our study, social functioning loaded on the physical health summary, and energy/fatigue loaded only on the mental health summary. Additionally, general health perception and pain loaded on both factors. In Lau et al. ' study [16], energy/fatigue loaded on the mental health summary (factor loading .71) and pain loaded on both the physical health summary (loading value of .54) and mental health summary (.26). In the Thai version of the MOS-HIV [22], while pain loaded mainly on the physical 
health summary (.62), it also loaded on the mental health summary (.35). The multidimensional nature of pain [43, 44], as well as the association of pain with mental health problems previously observed in HIVinfected adults, [45, 46] might explain this variation. For instance, the level of anxiety and depression was higher in patients with HIV reporting pain than in those who did not [45]. Similarly, HIV+ persons with diagnosed mood/anxiety and substance use disorders reported significantly higher levels of pain than did HIV+ persons without these comorbid conditions [47]. The loading of energy/fatigue on the mental health summary may be explained by a significant association between fatigue and depression previously observed in PLWHA $[48,49]$.

Furthermore, an examination of the MNSQ values from the Rasch analysis showed that the infit and outfit statistics were within acceptable ranges of 0.6-1.4, except for two items in the mental health summary, indicating the unidimensionality of the items within each factor.

However, in terms of the step parameter, step disorders were observed in 19 out of 34 items. This might be a result of the small sample size, and in fact, a sample size larger than 250 was suggested to ensure an adequate and stable estimation of parameters for Rasch analysis $[50,51]$. Furthermore, this might be related to the relatively good HIV-related condition of the study participants, as evidenced by their CD4 cell counts and viral load status, as well as their scores on K-MOS-HIV. Eleven out of the 19 items with step disorders were those which showed ceiling effects. The patterns of step disorder might be related to the relatively good functioning level of the participants. A small number of participants selected the lower level response category. Re-examination of the K-MOS-HIV with a sufficient number of participants with varying functioning levels is therefore necessary.

With regard to the known-group validity of the KMOS-HIV, a number of subscale scores differed significantly across groups with varying sociodemographic (i. e., age, marital status, employment, monthly income and insurance) and clinical characteristics (i.e., years since diagnosis, ART duration, CD4 cell counts, HIV RNA log, psychological, and medical comorbidity). With regard to sociodemographic variables, younger participants showed higher physical functioning and physical health summary scores. This inverse association between age and physical health observed in the present study is in line with the findings of a previous review [40]. In a study with 1191 HIV-positive patients, participants aged over 45 years reported lower scores on the physical domain of the HRQOL than did those aged under 34 years [52]. Relatedly, a previous study found that nearly half of older people with HIV had at least one major medical comorbidity, and a greater burden of co-morbidity was associated with a lower physical HRQOL [53]. Similarly, the independent effects of age observed for physical functioning and general health perceptions, as well as significant interaction effects of HIV and older age on daily functioning, were observed in PLWHA [54]. Further, in the present study, married people showed higher social functioning, energy/fatigue, mental health and mental health summary scores, which might be understood from a previously observed link between social support and better physical health summary and mental health summary in PLWHA $[40,55]$.

The results also suggested that being employed was associated with an overall higher HRQOL in PLWHA, which was in line with previous findings [56-58]. In fact, employment status was the strongest predictor of the five MOS-HIV health survey subscales scores in PLWHA in Canada [57]. Similarly, Rueda and colleagues [56] found that the effect of employment on QOL was comparable to that of higher HIV-related symptoms. They also suggested that the association between employment and QOL is to be understood in both directions, that is, overall good health being a necessary prerequisite to get or maintain employment (i.e., "the selection process"), and unemployment status causing lower QOL (i.e., "the causation process"). Moreover, insurance and income showed a similar pattern, which is in line with previous findings. For instance, lower income was associated with worse physical and mental health [5], and increased suicide risk [59].

Among clinical variables, there were no significant differences in the MOS-HIV scores in terms of CDC stage. However, as prior studies suggest that the association of advanced disease with physical health [40] and all the domains of the MOS-HIV except health transition [60], the ability of the MOS-HIV to discriminate HRQOL status according to the disease stage is unclear. For instance, the Spanish version of the MOS-HIV did not discriminate well between disease stages [14]. On the other hand, in a study with the Greek version of the MOS-HIV, scores on the physical functioning and pain subscales, and the physical health summary were significantly lower in individuals with AIDS compared to those with asymptomatic HIV+ [19].

Moreover, the present results indicated that the physical health summary scores as well as those on the subscales that loaded on the physical health summary such as general health perception, physical functioning, role functioning, and social functioning were significantly lower in groups with low CD4 cell counts or the group with a medical comorbidity. Similarly, the mental health summary scores as well as those on the subscales comprising the mental health summary, such as energy/fatigue and mental health, were lower in the group with a psychological comorbidity, confirming the known-group validity of the MOS-HIV. Although previous findings regarding 
the association between $\mathrm{CD} 4$ cell counts and $\mathrm{MOH}-\mathrm{HIV}$ scores are mixed, majority of these findings revealed a significant association of higher CD4 cell counts with higher HRQOL $[19,61]$. For instance, as compared to those with CD4 cell counts over 200, the group with CD4 cell counts less than 200 scored lower on the general health perception, physical functioning, pain, and energy/fatigue subscales, and the physical health summary in the MOS-HIV validation study conducted in Taiwan [42]. Similarly, patients with CD4 cell counts less than 200 showed lower physical well-being and overall QOL than did those with CD4 cell counts over 200 [62]. Additionally, in the present study, social functioning scores differed according to viral load status, which is partially consistent with a previously observed negative association of physical and mental health summary scores with viral loads [63]. The inverse association of comorbidity burden with overall HRQOL, particularly with physical QOL, was in line with that observed in previous studies on PLWHA [53, 64]. Furthermore, psychiatric comorbidity was related to lower mental health summary scores in the present study, which is consistent with previous findings that observed the association of depression with diminished HRQOL [60, 65].

The current results should be considered with their limitations. First, the cross-sectional nature of this study precludes any causal interpretation regarding the associations of sociodemographic and clinical characteristics with several dimensions of the MOS-HIV observed in this study. Additionally, due to the consecutive sampling procedure employed, the possibility of sample bias should be considered, and in fact, the ceiling effects in a number of subscale scores observed in this study might be related to the relatively good level of overall HIVrelated health condition of the participants. Those with a poorer condition were more likely to decline study participation. However, in terms of sex, age, and mode of transmission of HIV, the characteristics of our study participants are similar to those of people living with HIV/AIDS in South Korea [24]. To explain, $89.1 \%$ of our study participants were male, similar to $92.8 \%$ of males in people living with HIV/AIDS in 2016. In addition, in our study, $26.9 \%$ of the participants were aged below 40 years, $53.2 \%$ of them were aged between 41 and 60 years, and $19.9 \%$ of them were aged over 60 years, as compared to the percentages of 38.6, 48.1, and $13.3 \%$ reported among PLWHA in South Korea in 2016, respectively [24]. The percentages of heterosexual and same-sex transmission were 30.6 and $54.1 \%$, respectively, as compared to 58.4 and $41.5 \%$, respectively, which were reported among notified cases of HIV during 2007-2016 [24].

Moreover, for a HRQOL measure used in clinical practice, it is necessary to assess the sensitivity of the tool to detect changes in clinical status over time $[66,67]$. However, the test-retest reliability and the sensitivity of the
K-MOS-HIV to detect changes or responsiveness to symptom changes [68] was not tested in the present study, and they should be examined in a longitudinal and prospective study.

\section{Conclusion}

Despite these limitations, the present results suggest that the K-MOS-HIV is a reliable and valid measure of HRQOL in PLWHA, which would allow related research as well as cross-cultural comparisons on HRQOL in this population.

\begin{abstract}
Abbreviations
AIDS: Acquired immunodeficiency syndrome; CF: Cognitive functioning; CFA: Confirmatory factor analysis; CFI: Comparative fit index; EF: Energy/ fatigue; ESEM: Exploratory structural equation modeling; FAHI: Functional assessment of HIV infection quality of life instrument; GHP: General health perception; HAART: Highly active antiretroviral therapy; HD: Health distress; HIV: Human immunodeficiency virus:" HRQOL: Health-related quality of life:" HT: Health transition; INFIT: Information-weighted fit statistic; MH: Mental health; MHS: Mental health summary score; MNSQ: Mean square; MOSHIV: Medical outcomes study HIV health survey; OUTFIT: Outlier-sensitive fit statistic; PCM: Partial credit model; PF: Physical functioning; PHS: Physical health summary score;" PLWHA: People with HIV and AIDS; QL: Quality of life; RF: Role functioning; RMSEA: Root mean square error of approximation; SF: social functioning;i SRMR: Root mean square residual; WHOQOL-HIV BREF: World health organization quality of life-HIV-BREF
\end{abstract}

\section{Funding}

This work was supported by the Ministry of Education of the Republic of Korea and the National Research Foundation of Korea (NRF-2015S1A5A8016747).

\section{Availability of data and materials}

The datasets generated and analyzed during the current study are not publicly available but are available from the corresponding author on reasonable request.

\section{Authors' contributions}

EJS contributed to the conception and design of the work, analysis and interpretation of data for work, the draft of the manuscript and approved the final version of the manuscript. $\mathrm{HH}$ contributed to the analysis and interpretation of data for work, and approved the final version of the manuscript. SHL contributed to the acquisition of the data for work, the draft of the manuscript and approved the final version of the manuscript. NJK contributed to the design of the work, the acquisition of the data for work, the draft of the manuscript and approved the final version of the manuscript. ESK contributed to the acquisition of the data for work, the draft of the manuscript and approved the final version of the manuscript. JHB contributed to the acquisition of the data for work, the draft of the manuscript and approved the final version of the manuscript. KHS contributed to the acquisition of the data for work, the draft of the manuscript and approved the final version of the manuscript. BKS contributed to the acquisition of the data for work, the draft of the manuscript and approved the final version of the manuscript. HYP contributed to the acquisition of the data for work, the draft of the manuscript and approved the final version of the manuscript. KLS contributed to the acquisition of the data for work, the draft of the manuscript and approved the final version of the manuscript. $\mathrm{HH}$ contributed to the acquisition of the data for work, the draft of the manuscript and approved the final version of the manuscript. KML contributed to the acquisition of the data for work, the draft of the manuscript and approved the final version of the manuscript. BJH contributed to the conception and design of the work, interpretation of data for work, the draft of the manuscript and approved the final version of the manuscript.

\section{Ethics approval and consent to participate}

This study was approved by the respective Institutional Review Boards of the participating institutions. Informed consent was obtained from all participants included in the study. 


\section{Competing interests}

The authors declare that they have no competing interests.

\section{Publisher's Note}

Springer Nature remains neutral with regard to jurisdictional claims in published maps and institutional affiliations.

\section{Author details}

'Department of Psychology, Pusan National University, Busan, Republic of Korea. ${ }^{2}$ Department of Internal Medicine, Pusan National University School of Medicine, Busan, Republic of Korea. ${ }^{3}$ Department of Internal Medicine, Seoul National University College of Medicine, Seoul, Republic of Korea. ${ }^{4}$ Department of Internal Medicine, Seoul National University Bundang Hospital, Seongnam, Republic of Korea. ${ }^{5}$ Division of Infectious Diseases, Seoul National University Seoul Metropolitan Government Boramae Medical Center, Seoul, Republic of Korea. 'Department of Psychiatry, Sanggye Paik Hospital, Seoul, South Korea. ${ }^{7}$ Department of Psychiatry, Inje University College of Medicine, Busan, Republic of Korea. ${ }^{8}$ Department of Neuropsychiatry, Seoul National University Bundang Hospital, Seongnam, Republic of Korea. ${ }^{9}$ Department of Neuropsychiatry, Seoul National University Hospital, Seoul, Republic of Korea. ${ }^{10}$ Department of Psychiatry and Behavioral Sciences, Seoul National University College of Medicine, Seoul, Republic of Korea. ${ }^{11}$ Public Health and Medical Service, Seoul National University Hospital, Seoul, Republic of Korea.

\section{Received: 10 December 2017 Accepted: 30 April 2018}

\section{Published online: 15 May 2018}

\section{References}

1. Joint United Nations Programme on HIV/AIDS. Global AIDS update 2016. Geneva: UNAIDS; 2016

2. Murray CJ, Ortblad KF, Guinovart C, Lim SS, Wolock TM, Roberts DA, Dansereau EA, Graetz N, Barber RM, Brown JC. Global, regional, and national incidence and mortality for HIV, tuberculosis, and malaria during 1990-2013: a systematic analysis for the global burden of disease study 2013. Lancet. 2014:384:1005-70

3. Miners A, Phillips A, Kreif N, Rodger A, Speakman A, Fisher M, Anderson J, Collins S, Hart G, Sherr L. Health-related quality-of-life of people with HIV in the era of combination antiretroviral treatment: a cross-sectional comparison with the general population. Lancet HIV. 2014;1:e32-40.

4. Pedersen KK, Eiersted MR, Gaardbo JC, Pedersen M, Gerstoft J, Troseid M, Nielsen SD. Lower self-reported quality of life in HIV-infected patients on CART and with low comorbidity compared with healthy controls. J Acquir Immune Defic Syndr. 2015;70:16-22.

5. Hays RD, Cunningham WE, Sherbourne CD, Wilson IB, Wu AW, Cleary PD, McCaffrey DF, Fleishman JA, Crystal S, Collins R. Health-related quality of life in patients with human immunodeficiency virus infection in the United States: results from the HIV cost and services utilization study. Am J Med Sci. 2000;108:714-22

6. Lee RS, Kochman A, Sikkema KJ. Internalized stigma among people living with HIV-AIDS. AIDS Behav. 2002;6:309-19.

7. Herrmann S, McKinnon E, Hyland NB, Lalanne C, Mallal S, Nolan D, Chassany O, Duracinsky M. HIV-related stigma and physical symptoms have a persistent influence on health-related quality of life in Australians with HIV infection. Health Qual Life Outcomes. 2013;11:56.

8. Cunningham WE, Crystal S, Bozzette S, Hays RD. The association of healthrelated quality of life with survival among persons with HIV infection in the United States. J Gen Intern Med. 2005;20:21-7.

9. O'Connell KA, Skevington SM. An international quality of life instrument to assess wellbeing in adults who are HIV-positive: a short form of the WHOQOL-HIV (31 items). AIDS Behav. 2012;16:452-60.

10. Cella D, McCain N, Peterman A, Mo F, Wolen D. Development and validation of the functional assessment of human immunodeficiency virus infection (FAHI) quality of life instrument. Qual Life Res. 1996;5:450-63.

11. Wu AW, Hays RD, Kelly S, Malitz F, Bozzette SA. Applications of the medica outcomes study health-related quality of life measures in HIV/AIDS. Qual Life Res. 1997:6:531-54.

12. Clayson DJ, Wild DJ, Quarterman P, Duprat-Lomon I, Kubin M, Coons SJ. A comparative review of health-related quality-of-life measures for use in HIV/ AIDS clinical trials. PharmacoEconomics. 2006;24:751-65.
13. Holmes WC, Shea JA. Two approaches to measuring quality of life in the HIV/AIDS population: HAT-QoL and MOS-HIV. Qual Life Res. 1999;8:515-27.

14. Badia X, Podzamczer D, Garcia M, López-Lavid C, Consiglio E: the Spanish MOS-HIV and MQOL-HIV Validation Group. A randomised study comparing instruments for measuring health related quality of life in HIV-infected patients. AIDS. 1999:13:1727-35.

15. Copfer A, Ampel N, Hughes T, Gregor K, Dols C, Coons S, Colgan K, Wu A. The use of two measures of health-related quality of life in HIV-infected individuals: a cross-sectional comparison. Qual Life Res. 1996;5:281-6.

16. Lau JT, Tsui HY, Patrick LC, Rita CW, Molassiotis A. Validation of a Chinese version of the medical outcomes study HIV health survey (MOS-HIV) among Chinese people living with HIV/AIDS in Hong Kong. Qual Life Res. 2006;15:1079-89.

17. Huang Z-J, Tian M, Dai S-Y, Ye D-Q. Feasibility, reliability and validity of the Chinese simplified version of the MOS-HIV health survey among AIDS patients in China. Qual Life Res. 2013:22:403-7.

18. Scott-Lennox JA, Wu AW, Boyer JG, Ware JE Jr. Reliability and validity of French, German, Italian, Dutch, and UK English translations of the medical outcomes study HIV health survey. Med Care. 1999;37:908-25.

19. Stasinopoulou PG, Tzavara C, Dimitrakaki C, Georgiou O, Baraboutis IG, Skoutelis A, Papastamipoulos V, Tountas Y. Reliability and validity of the Greek translation of the MOS-HIV health survey in HIV-infected individuals. Qual Life Res. 2010;19:199-205.

20. Schifano P, Borgia P, Wu AW, Spadea T, Milanese G, Perucci CA. Validity and reliability of the Italian translation of the MOS-HIV health survey in persons with AIDS. Qual Life Res. 2003:12:1137-46.

21. Starace F, Cafaro L, Abrescia N, Chirianni A, Izzo C, Rucci P, Gd G. Quality of life assessment in HIV-positive persons: application and validation of the WHOOOL-HIV, Italian version. AIDS Care. 2002:14:405-15.

22. Ichikawa M, Natpratan C. Quality of life among people living with HIV/AIDS in northern Thailand: MOS-HIV health survey. Qual Life Res. 2004;13:601-10.

23. Mast T, Kigozi G, Wabwire-Mangen F, Black R, Sewankambo N, Serwadda D, Gray R, Wawer M, Wu A. Measuring quality of life among HIV-infected women using a culturally adapted questionnaire in Rakai district, Uganda. AIDS Care. 2004;16:81-94.

24. Choi JH, Kim, Sungnam, Park, Pyeong, Cho, Kyung Sook: HIV/AIDS notifications in Korea, 2016. Seoul: Division of TB\&HIV Control, Center for Disease Prevention; 2017.

25. Lee WK, Kim S-W, Kim H-I, Chang H-H, Lee J-M, Kim Y-J, Lee M-Y. Development of quality of life with WHOQOL-HIV BREF Korean version among HIV patients in Korea. J Kor Data Inform Sci Soc. 2014;25:337-47.

26. Wu A, Revicki D, Jacobson D, Malitz F. Evidence for reliability, validity and usefulness of the medical outcomes study HIV health survey (MOS-HIV). Qual Life Res. 1997:6:481-93.

27. Revicki DA, Sorensen S, Wu AW. Reliability and validity of physical and mental health summary scores from the medical outcomes study HIV health survey. Med Care. 1998;36:126-37.

28. Wu AW. MOS-HIV health survey users manual. Baltimore, MD: Johns Hopkins University; 1999

29. Koller M, Aaronson NK, Blazeby J, Bottomley A, Dewolf L, Fayers P, Johnson C, Ramage J, Scott N, West K. Translation procedures for standardised quality of life questionnaires: the European Organisation for Research and Treatment of Cancer (EORTC) approach. Eur J Cancer. 2007; 43:1810-20

30. Organization WH. WHOQOL-HIV instrument user's manual: scoring and coding for the WHOQOL-HIV instruments. Geneva: WHO; 2002.

31. Lohr KN. Assessing health status and quality-of-life instruments: attributes and review criteria. Qual Life Res. 2002;11:193-205.

32. Marsh HW, Morin AJ, Parker PD, Kaur G. Exploratory structural equation modeling: an integration of the best features of exploratory and confirmatory factor analysis. Annu Rev Clin Psychol. 2014;10:85-110.

33. Marsh HW, Muthén B, Asparouhov T, Lüdtke O, Robitzsch A, Morin AJ, Trautwein U. Exploratory structural equation modeling, integrating CFA and EFA: application to students' evaluations of university teaching. Struct Equ Model. 2009:16:439-76.

34. Asparouhov T, Muthén B. Exploratory structural equation modeling. Struct Equ Model. 2009:16:397-438.

35. Schreiber JB, Nora A, Stage FK, Barlow EA, King J. Reporting structural equation modeling and confirmatory factor analysis results: a review. J Educ Res. 2006;99:323-38.

36. Masters GN. A Rasch model for partial credit scoring. Psychometrika. 1982; 47:149-74. 
37. Embretson SE, Reise SP. Item response theory. Mahwah: Lawrence Erlbaum Associates; 2013.

38. Wright BD. Reasonable mean-square fit values. Rasch Meas Trans. 1994;8: 370.

39. Kim BS, Hong S. A psychometric revision of the Asian values scale using the Rasch model. Meas Eval Couns Dev. 2004:37(1):15-27.

40. Degroote S, Vogelaers D, Vandijck DM. What determines health-related quality of life among people living with HIV: an updated review of the literature. Arch Public Health. 2014;72:40.

41. Little RJ. A test of missing completely at random for multivariate data with missing values. J Am Stat Assoc. 1988;83:1198-202.

42. Hsiung P-C, Fang C-T, Lee K-L, Sheng W-H, Wu C-Y, Wang J-D, Yao G. Validation of the medical outcomes study HIV (MOS-HIV) health survey among HIV-infected patients in Taiwan. Qual Life Res. 2011;20:281-6.

43. Del Borgo C, Izzi I, Chiarotti F, Del Forno A, Moscati AM, Cornacchione E, Fantoni M. Multidimensional aspects of pain in HIV-infected individuals. AIDS Patient Care STDs. 2001;15:95-102.

44. Dworkin RH, Bruehl S, Fillingim RB, Loeser JD, Terman GW, Turk DC. Multidimensional diagnostic criteria for chronic pain: introduction to the ACTTION-American pain society pain taxonomy (AAPT). J Pain. 2016;17:T1-9.

45. Aouizerat BE, Miaskowski CA, Gay C, Portillo CJ, Coggins T, Davis H, Pullinger CR, Lee KA. Risk factors and symptoms associated with pain in HIV-infected adults. J Assoc Nurses AIDS Care. 2010;21:125-33.

46. Miaskowski C, Penko JM, Guzman D, Mattson JE, Bangsberg DR, Kushel MB. Occurrence and characteristics of chronic pain in a community-based cohort of indigent adults living with HIV infection. J Pain. 2011;12:1004-16.

47. Tsao JC, Soto T. Pain in persons living with HIV and comorbid psychological and substance use disorders. Clin J Pain. 2009;25:307.

48. Voss JG, Portillo CJ, Holzemer WL, Dodd MJ. Symptom cluster of fatigue and depression in HIV/AIDS. J Prev Interv Community. 2007;33:19-34.

49. Leserman J, Barroso J, Pence B, Salahuddin N, Harmon J. Trauma, stressful life events and depression predict HIV-related fatigue. AIDS Care. 2008;20:1258-65.

50. Hsiao Y-Y, Shih C-L, Yu W-H, Hsieh C-H, Hsieh C-L. Examining unidimensionality and improving reliability for the eight subscales of the SF-36 in opioiddependent patients using Rasch analysis. Qual Life Res. 2015;24:279-85.

51. Chen W-H, Lenderking W, Jin Y, Wyrwich KW, Gelhorn H, Revicki DA. Is Rasch model analysis applicable in small sample size pilot studies for assessing item characteristics? An example using PROMIS pain behavior item bank data. Qual Life Res. 2014;23:485-93.

52. Pereira M, Canavarro MC. Gender and age differences in quality of life and the impact of psychopathological symptoms among HIV-infected patients. AIDS Behav. 2011;15:1857-69.

53. Rodriguez-Penney AT, ludicello JE, Riggs PK, Doyle K, Ellis RJ, Letendre SL, Grant I. Woods, the HIV neurobehavioral research program group SP: comorbidities in persons infected with HIV: increased burden with older age and negative effects on health-related quality of life. AIDS Patient Care STDs. 2013;27:5-16.

54. Morgan EE, ludicello JE, Weber E, Duarte NA, Riggs PK, Delano-Wood L, Ellis R, Grant I, Woods SP, Group HNRP. Synergistic effects of HIV infection and older age on daily functioning. J Acquir Immune Defic Syndr. 2012;61(1999):341.

55. Bekele T, Rourke SB, Tucker R, Greene S, Sobota M, Koornstra J, Monette L, Rueda S, Bacon J, Watson J. Direct and indirect effects of perceived social support on health-related quality of life in persons living with HIV/AIDS. AIDS Care. 2013;25:337-46.

56. Rueda S, Raboud J, Mustard C, Bayoumi A, Lavis JN, Rourke SB. Employment status is associated with both physical and mental health quality of life in people living with HIV. AIDS Care. 2011;23:435-43.

57. Worthington $\mathrm{C}$, Krentz $\mathrm{H}$. Socio-economic factors and health-related quality of life in adults living with HIV. Int J STD AIDS. 2005;16:608-14.

58. Nobre N, Pereira M, Roine RP, Sintonen H, Sutinen J. Factors associated with the quality of life of people living with HIV in Finland. AIDS Care. 2017;29:1074-8.

59. Jia C-X, Mehlum L, Qin P. AIDS/HIV infection, comorbid psychiatric illness, and risk for subsequent suicide: a nationwide register linkage study. J Clin Psychiatry. 2012;73:1315.

60. Briongos Figuero L, Bachiller Luque P, Palacios Martin T, González Sagrado $M$, Eiros Bouza J. Assessment of factors influencing health-related quality of life in HIV-infected patients. HIV Med. 2011;12:22-30.
61. Bing EG, Hays RD, Jacobson L, Chen B, Gange S, Kass N, Chmiel J, Zucconi SL. Health-related quality of life among people with HIV disease: results from the multicenter AIDS cohort study. Qual Life Res. 2000;9:55-63.

62. Hasanah C, Zaliha A, Mahiran M. Factors influencing the quality of life in patients with HIV in Malaysia. Qual Life Res. 2011;20:91-100.

63. Stangl AL, Bunnell R, Wamai N, Masaba H, Mermin J. Measuring quality of life in rural Uganda: reliability and validity of summary scores from the medical outcomes study HIV health survey (MOS-HIV). Qual Life Res. 2012;21:1655-63.

64. Jia H, Uphold CR, Zheng Y, Wu S, Chen GJ, Findley K, Duncan PW. A further investigation of health-related quality of life over time among men with HIV infection in the HAART era. Qual Life Res. 2007;16:961-8.

65. Millar BM, Starks TJ, Gurung S, Parsons JT. The impact of comorbidities, depression, and substance use problems on quality of life among older adults living with HIV. AIDS Behav. 2017;21:1684-90.

66. Delate T, Coons SJ. The use of 2 health-related quality-of-life measures in a sample of persons infected with human immunodeficiency virus. Clin Infect Dis. 2001;32:e47-52.

67. Peterman A, Cella D, Mo F, McCain N. Psychometric validation of the revised functional assessment of human immunodeficiency virus infection (FAHI) quality of life instrument. Qual Life Res. 1997;6:572-84.

68. Burgoyne RW, Rourke SB, Behrens DM, Salit IE. Long-term quality-of-life outcomes among adults living with HIV in the HAART era: the interplay of changes in clinical factors and symptom profile. AIDS Behav. 2004;8:151-63.

\section{Ready to submit your research? Choose BMC and benefit from:}

- fast, convenient online submission

- thorough peer review by experienced researchers in your field

- rapid publication on acceptance

- support for research data, including large and complex data types

- gold Open Access which fosters wider collaboration and increased citations

- maximum visibility for your research: over $100 \mathrm{M}$ website views per year

At BMC, research is always in progress.

Learn more biomedcentral.com/submissions 